\title{
Experimental investigation on the motion response of a novel floating desalination plant for Egypt
}

\author{
Islam Amin ${ }^{1,2}$, Saishuai Dai ${ }^{2}$, Selda Oterkus ${ }^{2}$, Sandy Day ${ }^{2}$, Erkan Oterkus ${ }^{2 *}$ \\ 1 Department of Naval Architecture and Marine Engineering, Port Said University, Egypt \\ 2 Department of Naval Architecture, Ocean and Marine Engineering, University of Strathclyde, UK; \\ *Corresponding author: erkan.oterkus@strath.ac.uk; Tel.: +44-141-548-3876
}

\begin{abstract}
Increasing water demand in remote coastal areas in Egypt has shifted attention to the role of floating desalination plants to alleviate water shortages. A novel mobile floating desalination plant is proposed for Ras Ghareb city in Egypt. The compatibility between floater natural periods and the energy excitation range of waves in deployment area can lead to resonance responses. Therefore, understanding the motions behaviour among waves of such floaters at a particular location is important for its safety, performance and operation. The goal of the present study is to investigate the suitability of proposed concept for Egyptian environment conditions by characterising the behaviour of the plant motion responses during its entire deployment conditions. Based on full scale design of the proposed plant, experimental study over a range of wave heights and frequencies was performed in the present study using a 1:100 scale model test. In order to identify the plant natural frequency and damping ratio, free decay and swinging tests were performed for different load conditions. Different wave heights were tested during the experiments in order to investigate the effect of wave height on the heave and pitch responses at plant natural frequencies. The experimental test results were compared with numerical results from frequency domain program HydroD implemented in Sesam DNV GL software package. Results show that heave and pitch motion responses give the closest agreement between the measurements and numerical predictions over the whole range of wave periods except the peak spike. The proposed cylindrical FDP is compared against a conventional ship FPSO concept widely used for offshore freshwater production and it was concluded that new cylindrical FDP shows better motion responses compared to conventional ship FPSO concept in same wave bands in Egypt.
\end{abstract}

Key Words: Offshore platform; seawater desalination; dynamic response of offshore structure.

\section{Introduction}

Supply of freshwater has attracted worldwide interest due to serious water shortage problems in many countries. Desalination of seawater is a promising approach which can help the world to solve freshwater shortage problem and meet global water demand. Although conventional land-based desalination plants are vital for economic development and social stability, they need extensive distribution and supplying networks, have high cost due to expensive infrastructure and not economically viable in remote areas. On the other hand, Mobile Floating Desalination Plants (FDP) can be useful and economic alternative solution especially for islands and remote coastal cities far from national water grid.

Although, FDP concept is a relatively young technology compared to land-based desalination plants, a number of FDP concept powered by fossil fuel and nuclear power have been established and successfully tested in commercial projects in different countries. For example, FDP concept powered by fossil fuel was discussed and compared with conventional land based plants by Fadel [1]. The study presented a fully seagoing desalination ship called RUMAITH and serviced in Abu Dhabi. The vessel carries two $1250 \mathrm{~m}^{3} /$ day thermal distiller systems powered by two diesel generators and the vessel is equipped with full marine and navigation facilities. Moreover, Chouaki [2-3] proposed a floating desalination ship powered by liquefied natural gas (LNG) for western Mediterranean Sea. FDP ship powered by nuclear power especially in Russia was investigated in [4-5]. 
Regarding non-ship-shaped FDP concepts, different FDP concepts were proposed. The Ydriada MUP plant located in Greece is a very promising prototype of a small unconventional concept of an offshore FPD unit driven by a wind turbine [6]. The plant contains small vertical cylinder pontoons connected to each other and the center pontoon supports a small desalination unit and a wind turbine. State-of-theart of existing design and analytical procedures of floating nuclear plants was presented by Babu [5]. Based on his comparative study, five different concepts were inspired from oil and gas industry, namely, floating ship form hull, floating submarine hull, bottom caisson, artificial islands and floating platform barge mounted plant. Another study for an offshore nuclear desalination plant was performed at MIT in 2017. Multiple platform designs were evaluated to compare the differences in seakeeping and stability such as cylinder, octagonal, and oval platform shapes.

The floating cylindrical platforms have been extensively studied for different industrial applications. Several review studies on marine cylindrical floaters have been performed, such as cylindrical floating breakwater system [7], oil and gas platforms and renewable energy devices including wave energy converter and wind turbine foundations [8]. Cylindrical Floating Production Storage and Offloading system (FPSO) has been used in offshore oil and gas industry since the first appearance of this design, Sevan Piranema, which was constructed by Sevan Marine Company in 2006 [9]. Due to their cylindrical shapes, cylindrical FPSO often experiences significant heave and pitch motions. As these large motions will affect the safety of these structures, significant effort has been spent to improve their dynamic performance in the case of wave loading. The employment of devices to minimize motion such as moonpools, skirts and beaches has been studied by researchers from University of São Paulo in order to reduce the platform motion [10]. Experimental study of vortex-induced motion was carried out for a cylindrical FPSO designed for Gulf of Mexico [11]. Motion behaviour of the cylindrical FPSO Sevan Piranema was investigated considering Brazilian environmental conditions [12]. Extensive experimental studies on the motion responses of a cylindrical platform under random and freak waves have been conducted by Pan el al. [13]. The hydrodynamic responses, characterized by 6 degrees of freedom motions, wave run-up and air-gap of a three cylindrical column semi-submersible platform in random sea conditions were experimentally investigated by Lu et al. [14]. Moreover, forced heave and surge motion of axisymmetric vertical cylindrical bodies with flat and rounded bases have been numerically investigated by Hanbin et al. [15]. A novel pneumatic platform configuration to damp the motion was proposed by Cheung et al. [16]. This configuration is composed of an array of open-bottom vertical cylinders trapping pressurized air that displaces the water. Hydrodynamic response of a pneumatic floating platform was studied both numerically and experimentally. Experimental study of hydrodynamic responses of a single floating storage platform with internal fluid tank was performed by Chi et al. [17]. An experimental study on the hydrodynamic performance of a new type of deep draft multi-column FPSO was presented in [18]. The FPSO's motion responses in operation condition and self-survival condition were studied. In order to investigate the performance limitations of traditional ship type and cylindrical FPSO, a new concept of sandglass-type FPSO was proposed by Wang et al. [19]. The experimental and numerical studies showed that the sandglass-type design can obviously improve the hydrodynamic performance of FPSO [20, 21 and 22].

With a successful and rapid development of offshore industry, there is an increased interest in investigating the technological and economical feasibility of combining offshore industrial applications. The circular spar torus combination, the semi-submersible flap combination and the oscillating water column array with a wind turbine were studied in detail by numerical and experimental methods [23]. Another experimental study of wave energy converters concentrically arranged and attached on a floating offshore platform model was presented by Kamarlouei et al. [24]. The 1:27 scale model has been designed, built and tested in two main situations, without and with twelve cone shape wave energy converters. A similar study presented a novel concept by combining a tension leg platform type floating wind turbine and a heave-type wave energy converter [25]. Based on Sevan's cylindrical platform, conceptual design of integrated floating power plant and carbon capture process have been developed [26]. The dynamic behaviour of the platform is likely to move smoothly around their vertical axes with 
a period of $20 \mathrm{~s}(0.05 \mathrm{~Hz})$. Another novel off-grid floating desalination plant powered by wind turbine was inspired based on Sevan's cylindrical platform for remote coastal areas [27]. The proposed conceptual design is different from FPSO Sevan in moon pool configuration and riser systems.

In the present study, a novel cylindrical on-grid FDP concept is proposed for Egypt. Mobile cylindrical platform can serve at different places in Red Sea depending on the water demand. The proposed plant has social and economic benefits for Egypt. Ras Ghareb city was selected for the proposed FDP concept due to its abundant high solar irradiation and high water demand for civil and industry needs [28-29]. Understanding the motion behaviour of the proposed cylindrical plant in different load conditions is important for the safety, performance and operation of such plant. Therefore, identification of the plant's natural frequency, damping ratio and motion response are experimentally and numerically performed for different load conditions and wave heights. The present study is structured as follows: Section 2 introduces the FDP concept; Section 3 presents the experimental study; Section 4 performs the numerical solution; finally, Section 5 discusses the results.

\section{Proposed FDP concept}

\subsection{General description of FDP system}

The cylindrical hull platform was selected to meet the Egyptian environmental conditions based on some technical reasons. First of all, the cylindrical platform is considered as a barge platform concept which is distinguished with large displacement needed for storage capacity, large water plane area leading to smaller draught and ability to be deployed at a wider range of sites. Moreover, mooring and installation costs of such floaters are expected to be small compared to those of other concepts due to its symmetrical shape and simple construction which make it well-suited for manufacturing at Egyptian shipyards. On the other hand, the semisubmersible concept was excluded because of its complex structure and uncertainty in terms of the stability during loading and unloading operation. Also, the tension leg platform (TLP) and Spar configurations do not meet the mobility function for the unit due to their large drafts and technical difficulties during the towing process.

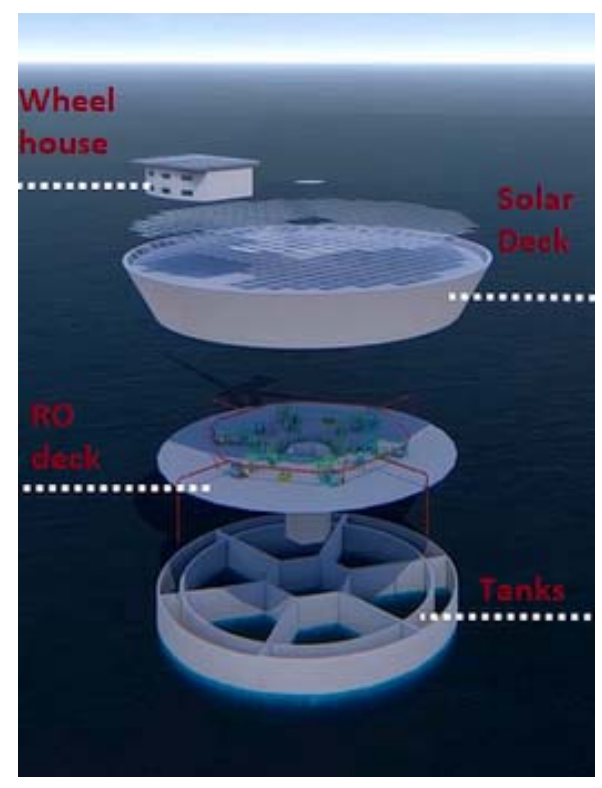

Figure 1: Proposed floating desalination plant (FDP) concept

The proposed FDP concept is equipped with a desalination plant, storage tanks and photovoltaics deck as shown in Fig. (1). The Reverse Osmosis (RO) desalination system was selected for the proposed FDP concept. The total desalination capacity is $10,000 \mathrm{~m}^{3} /$ day which is distributed over six RO modules and each has a capacity of $2,000 \mathrm{~m}^{3} /$ day with one of the six modules being a backup module. The cross section of the proposed FDP concept is illustrated in Figure (2). 
The operation of the desalination system can be summarized in four main steps:

- First step is to intake seawater by feed pump through marine sea chests at the lower level of the platform. Seawater then passes through screen filters to be stored in raw water tank. The middle moon pool configuration in Sevan Piranema was replaced with closed feeding raw water tank and pre-treatment partition in the proposed design. The proposed novel arrangement will allow the feeding seawater to enter the raw tank under the pressure of water head around the plant.

- The second step is pre-treatment of seawater by pumping water to pass through a dual-media filter to remove the microflocs which have formed.

- The third step is RO desalination process which contains high pressure pumps placed lower the main deck in order to eliminate the pressure head. Desalted water is then transferred to freshwater storage tanks which is distributed under desalination units to drop the desalted water by gravity.

- The fourth step is brine disposal through underwater diffuser to dispose the concentrated salted water far from raw water intake.

- Last step is post treatment and transferring to shore facility using marine hoses.

The required energy for the desalination process is supplied by direct connection to the electricity shore grid through underwater cable and solar power system.

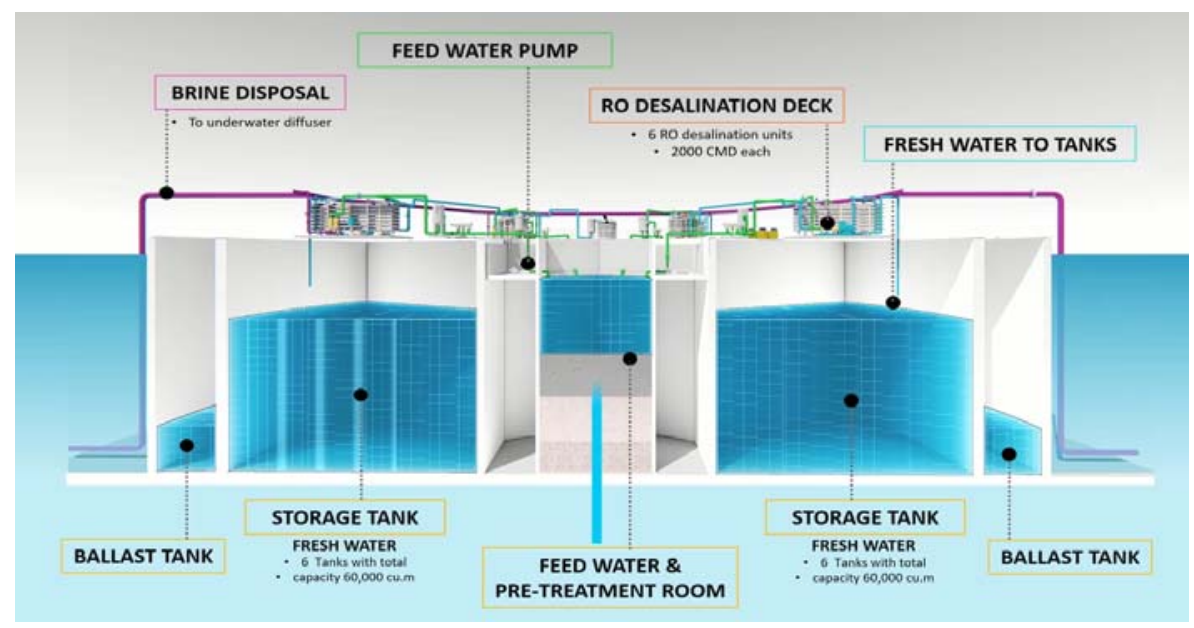

Figure 2: Cross section of the proposed FDP concept.

\subsection{Location}

FDP site selection is affected by different factors and constraints based on many social, economic and topographic set of data. Egypt has approximately $3000 \mathrm{~km}$ of coastal zones lied on the Mediterranean Sea $(1150 \mathrm{~km})$ and the Red Sea $(1200 \mathrm{~km})$ [30]. While Egyptian coastline has elements of development, it is remote from national grid of water. Based on previous site selection study [27], Ras Ghareb was selected to be the base of the proposed FDP concept. The mobility proposed concept can also serve different cities in Red Sea region depending on water demands in this area. Red Sea area has three major characteristics; high water demands for civil, tourism and industrial reasons, sufficient water depth and high solar radiation potential. Ras Ghareb city lies at Latitude: $28.33^{\circ} \mathrm{N}$, Longitude: $33^{\circ} \mathrm{E}$ and Altitude: $56 \mathrm{~m}$. Height of anemometer is $24.5 \mathrm{~m}$ above the ground. The average water depth in front of Ras Ghareb coastline is $50 \mathrm{~m}$ at a distance of $2 \mathrm{~km}$ from the coastline and outside this distance the water depth is considered as deep water [29]. Ras Ghareb is equipped with crude oil terminal which has anchorage area and has suitable infrastructure to store and supply freshwater. Two marine hoses of 12inch diameter are proposed to transfer the production water to the shore facility at a rate of $1000 \mathrm{~m}^{3} / \mathrm{hr}$. The site location is shown in Figure (3). 


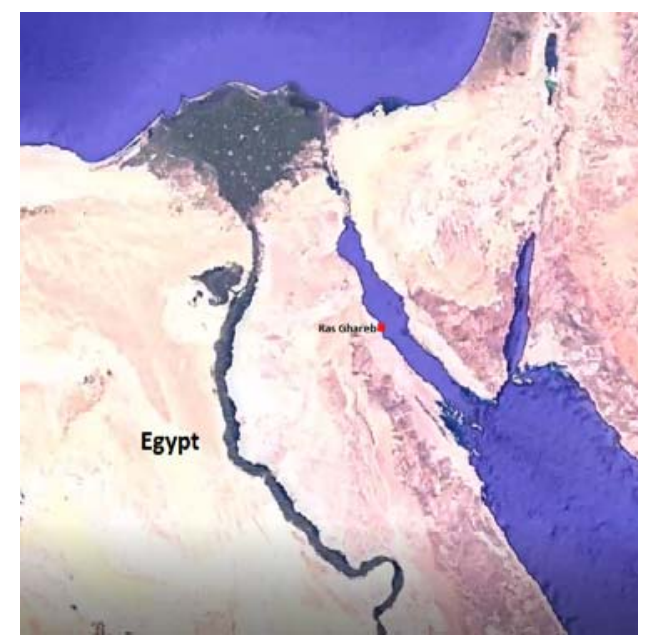

Figure 3: FDP location at Ras Ghareb city

\subsection{Environmental loads}

In order to characterise the behaviour of the proposed FDP concept during its entire operating conditions, the appropriate wave conditions in the deployment area (Red Sea in Egypt) was selected based on an analysis of the proposed site. Two parameters Pierson Moskowitz (PM) spectra for a range of wave height and periods values were calculated as

$S_{P M}(\omega)=\frac{5}{16} \cdot H_{S} \omega_{P}^{4} \cdot \omega^{-5} \exp \left[-\frac{5}{4}\left(\frac{\omega}{\omega_{P}}\right)^{-4}\right]$

where $\omega_{P}=2 \pi / T_{P}$ is the angular spectral frequency.

$\omega=2 \pi f$

where $H_{S}$ is the significant wave height and $T_{P}$ wave period.

Based on the database and historical weather information in Red Sea zone, significant wave height and wave period were determined for a 1-year return period in this area producing values of $2.15 \mathrm{~m}$ for the wave height and $5.08 \mathrm{~s}$ for the wave period. Moreover, the maximum wave height and time period for one year are $5.18 \mathrm{~m}$ and $6.5 \mathrm{~s}$ and for a 100-year return period, they are $7.92 \mathrm{~m}$ and $8 \mathrm{~s}$, respectively [27].

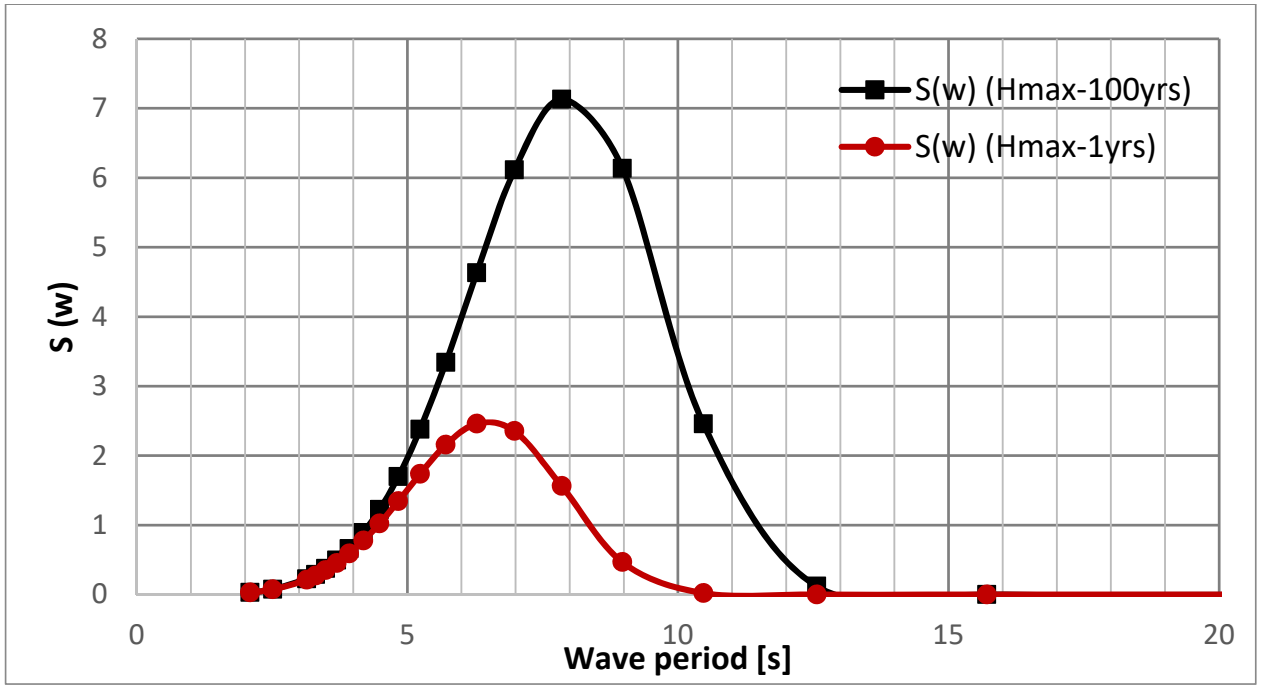

Figure 4. Wave spectrum of the selected location. 
As shown in Figure 4, based on the wave spectrum of the selected location, the wave bands are in range of 3 to $12.5 \mathrm{sec}$ and the peak of maximum wave spectrum is $8 \mathrm{~s}(0.08 \mathrm{~Hz})$. The proposed FDP concept should be out of the wave band range to avoid large dynamic responses [31].

\section{Experiment}

In order to investigate the motion responses of the FDP, a 1:100 scale model was designed, constructed at the Kelvin Hydrodynamics Laboratory (KHL) of the University of Strathclyde, and tested in the KHL towing tank.

\subsection{Facility and test configuration}

The KHL towing tank has a dimension of $76 \mathrm{~m} \times 4.6 \mathrm{~m} \times 2.5 \mathrm{~m}$ (length, width, depth). The water depth was set to $1.91 \mathrm{~m}$ for the present tests. For the presented experiments, regular sinusoidal waves were generated by multiflap type wave maker built by Edinburgh Design Ltd company [32]. The force controlled wave maker is able to actively absorb the radiation and the reflection from the opposite direction of the wave propagation, preventing secondary reflection from the wave maker. At the other end of the tank, there is a $14 \mathrm{~m}$ long slope type wave beach extending to the bottom of the tank, offering a reflection coefficient typically less than $5 \%$ within interested wave frequency range.

The FDP model was moored by four elastic mooring lines at the centre of the towing tank. The elastic mooring lines has similar density of the water and thus floats on the water surface. This arrangement considered as a soft mooring which means that mooring lines only provides restoring force in the surge and sway direction. The plan and profile view of the tank showing the experimental set up is depicted in Figure 5.

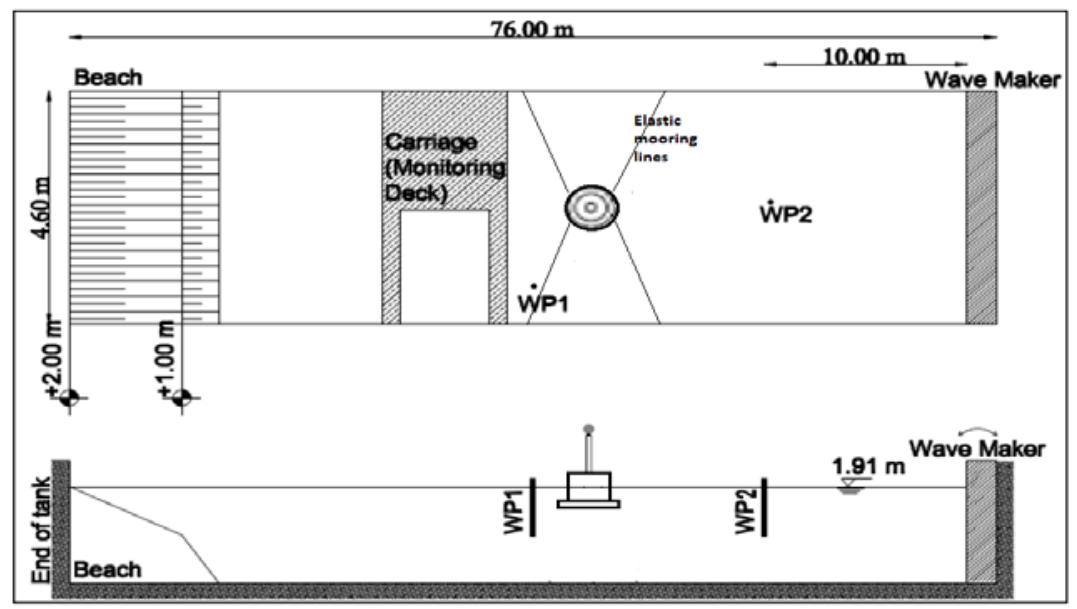

Figure 5: Schematic view of the model in the tank

\subsection{Instruments and sensors}

The wave elevation was monitored and recorded using one probe placed around $10 \mathrm{~m}$ from the wave maker and another one in line with the model. To capture the motion of the platform, the six degree of freedom QUALISYS motion camera system, shown in Figure 6, is used. It is comprised of four illuminated balls infra-red reflectors strategically placed on the model. The coordinates of the balls in 3D space were registered by four high speed capture cameras suitably located near the model at the edge of the carriage. The six degrees of freedom were adapted with principal coordination system and three motions were calculated and output in real time through Spike2 V9.06 data converter. 


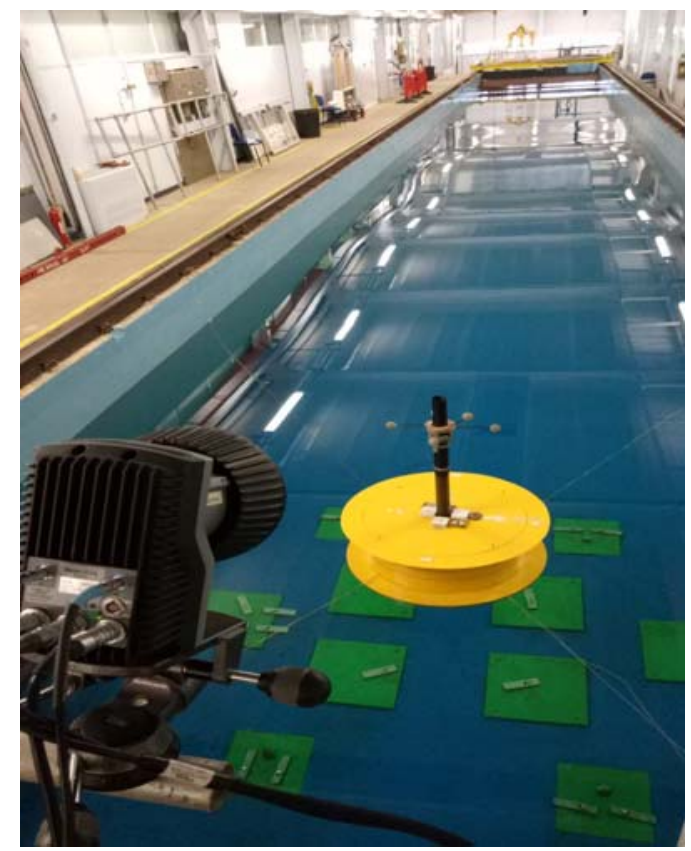

Figure 6: Qualisys camera system at the edge of tank carriage and the illuminated balls infra-red reflectors.

\subsection{Model description}

The model of the plant was constructed based on proposed full scale design of FDP which has been described in section 2 and presented in Table 1. The principle dimensions of the tank and capability of the wave maker are the most critical factors which determine the scale factor to be used for the experiments. In order to have the target values of minimum block coefficient, the model scale was selected to be 1:100 from the full scale design $(\lambda=100)$. Tank blockage ratio is equivalent to model diameter over the tank width and estimated at 0.152 . The platform hull is a floating cylinder with an outer diameter of $0.7 \mathrm{~m}$ and a total height $\mathrm{H}$ of $0.32 \mathrm{~m}$. The platform deck has an extended diameter of $0.875 \mathrm{~m}$, while the heave plate installed at the bottom of the platform is with an outer diameter of 0.875 $\mathrm{m}$ and a thickness of $0.025 \mathrm{~m}$. Detailed dimensions of the components can be found in Table 1. Sketch of the main platform can be found in Figure 7. The main hull was manufactured by fibre glass with the aid of a self-made cylindrical mould with one end open. The wooden heave plate was glued to the bottom of the hull. The middle tower, which carries the illuminated balls, was made of carbon fibre offthe-shelf and was connected to the hull bottom via a flange fixed to the bottom. The wooden model deck was designed to be removable to allow changing load conditions easily. The removable cover was staked by silicon to make the model waterproof and avoid any leakages during experiments.

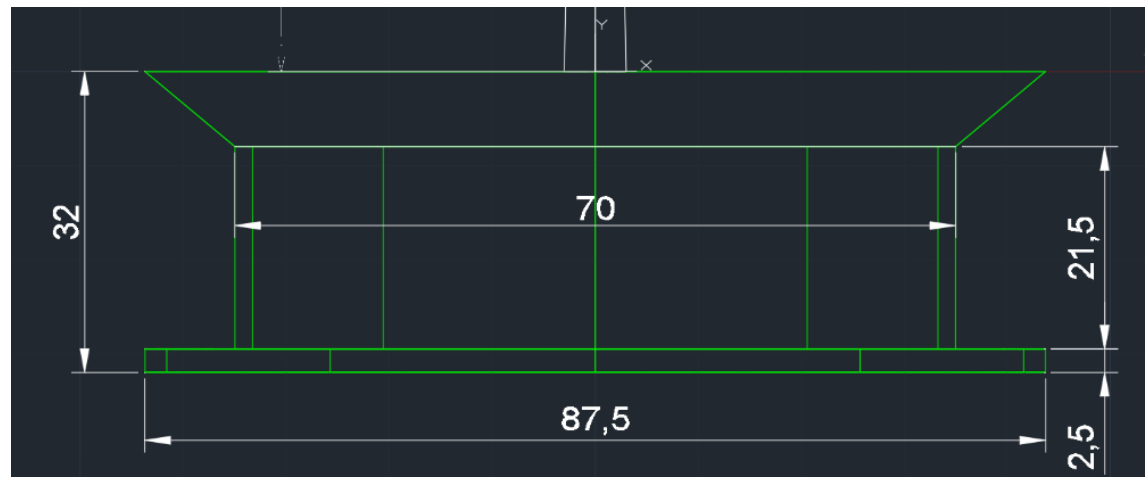

Figure 7: Full scale design dimensions 
Table 1: Full scale design and 1:100 model dimensions

\begin{tabular}{|l|l|l|}
\hline Particulars & Full scale design & Model $(1: 100)$ \\
\hline Main deck diameter & $87.5 \mathrm{~m}$ & 0.875 \\
\hline Main hull diameter & $70.0 \mathrm{~m}$ & 0.700 \\
\hline Heave plate diameter & $87.5 \mathrm{~m}$ & 0.875 \\
\hline Heave plate height & $2.50 \mathrm{~m}$ & 0.025 \\
\hline Hull depth & $32.00 \mathrm{~m}$ & 0.320 \\
\hline Overall height & $116.00 \mathrm{~m}$ & 1.160 \\
\hline Tower height & $84.00 \mathrm{~m}$ & 0.840 \\
\hline Wave frequency $(\mathrm{Hz})$ & From 0.03 to 0.14 & From 0.300 to 1.400 \\
\hline Wave period range (s) & From 7.14 to 33.33 & From 0.714 to 3.333 \\
\hline
\end{tabular}

\subsection{Loading conditions}

The floating plant mass estimation and distribution were arranged in 3D model using Sesam DNV GL modeller, GeniE. Three different load conditions were considered, namely, light-ship, ballast, full load conditions, as shown in Table 2. Moment of inertia was numerically estimated for all cases in GeniE program and the results are shown in Table 3. The lightship weight was calculated at 25,000 tons by considering all hull and equipment items for the full scale design. The model target weight is $25.04 \mathrm{~kg}$ according to the Froude scaling law. The model structural mass weight was measured after manufacturing as $24.30 \mathrm{~kg}$. In order to achieve the light-ship weight, $740 \mathrm{~g}$ ballast weight was added on the platform deck. For the ballast condition, $36.85 \mathrm{~kg}$ ballast weight was added inside the model as shown in Figure 8. In the full load case, $61.92 \mathrm{~kg}$ ballast weight was added and distributed to achieve the model target weight.

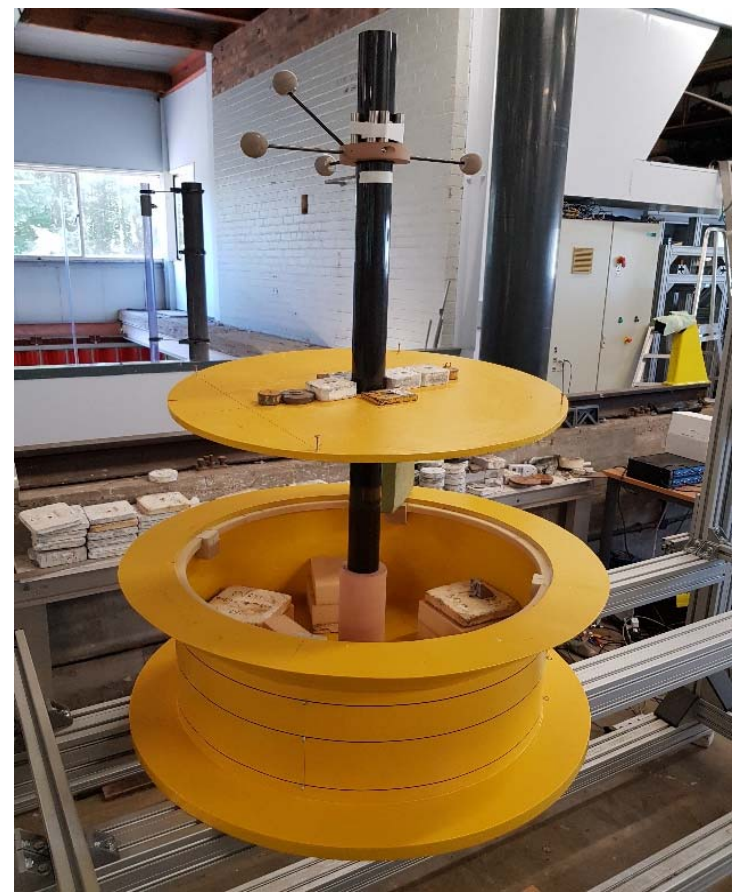

Figure 8: Swing table and ballast weight distribution. 
Table 2: Platform mass properties for different load conditions

\begin{tabular}{|l|l|l|l|l|}
\hline Load condition & Specification & $\begin{array}{c}\text { Full scale } \\
\text { design }\end{array}$ & Model & Unit \\
\hline 1-Light-ship condition & Draft & 5.25 & 0.0525 & $\mathrm{~m}$ \\
\cline { 2 - 5 } & $\begin{array}{l}\text { Volume of } \\
\text { displacement }\end{array}$ & 25000.00 & 0.025 & $\mathrm{~m}^{3}$ \\
\cline { 2 - 5 } & Displacement & 25625000 & 25.000 & $\mathrm{~kg}$ \\
\cline { 2 - 5 } & VCG & 18.99 & 0.189 & $\mathrm{~m}$ \\
\hline 2-Full load condition & Draft of & 21.00 & 0.210 & $\mathrm{~m}$ \\
\cline { 2 - 5 } & $\begin{array}{l}\text { Volume } \\
\text { displacement }\end{array}$ & 86217.00 & 0.086 & $\mathrm{~m}^{3}$ \\
\cline { 2 - 5 } & Displacement & 88375000 & 86.219 & $\mathrm{Kg}$ \\
\cline { 2 - 5 } & VCG & 14.03 & 0.140 & $\mathrm{~m}$ \\
\hline 3-Ballast condition & Draft & 14.44 & 0.144 & $\mathrm{~m}$ \\
\cline { 2 - 5 } & $\begin{array}{l}\text { Volume of } \\
\text { displacement }\end{array}$ & 61151.00 & 0.061 & $\mathrm{~m}$ \\
\cline { 2 - 5 } & Displacement & 62680000 & 61.151 & $\mathrm{Kg}$ \\
\cline { 2 - 5 } & VCG & 13.89 & 0.138 & $\mathrm{~m}$ \\
\hline
\end{tabular}

Table 3: Full scale platform moment of inertia for different load conditions.

\begin{tabular}{|l|l|l|l|l|l|l|}
\hline $\begin{array}{l}\text { Loading } \\
\text { conditions }\end{array}$ & Ixx (units) & Iyy & Izz & Ixy & Ixz & Iyz \\
\hline Light-ship & $1.592 \mathrm{E}+10$ & $1.604 \mathrm{E}+10$ & $1.853 \mathrm{E}+10$ & $1.559 \mathrm{E}+7$ & $2.953 \mathrm{E}+7$ & $4.387 \mathrm{E}+7$ \\
\hline Full load & $2.881 \mathrm{E}+10$ & $2.892 \mathrm{E}+10$ & $4.252 \mathrm{E}+10$ & $5.965 \mathrm{E}+7$ & $2.315 \mathrm{E}+7$ & $4.416 \mathrm{E}+7$ \\
\hline Ballast & $3.452 \mathrm{E}+10$ & $3.463 \mathrm{E}+10$ & $5.342 \mathrm{E}+10$ & $5.965 \mathrm{E}+7$ & $2.296 \mathrm{E}+7$ & $4.422 \mathrm{E}+7$ \\
\hline
\end{tabular}

\subsection{Test matrix}

The platform model was tested over a wave period range from 0.714 to $3.333 \mathrm{~s}$ corresponding to full scale wave period from 7.14 to $33.33 \mathrm{~s}$ for each of the above mentioned load conditions. In order to explore the effectiveness of wave height on the motion performance of the floating plant, a further set of tests were carried out at different wave heights.

The waves were with an initial wave amplitude of $0.215 \mathrm{~m}$ and a frequency range of covering $0.3 \mathrm{~Hz}$ to $1.4 \mathrm{~Hz}$. A set of 148 runs were predefined to cover the whole frequency band. Depending on the preliminary results, further 54 set of tests were added to refine the response results near peaks of resonances. The test time length was in average 5 minutes in total starting simultaneously with the oscillating wave maker. A settling time period of 5 minutes was considered between the tests to improve wave's quality and side absorbers were used to prevent transverse wave interference.

Table 4: Summary of model test matrix

\begin{tabular}{|l|l|l|l|}
\hline Test type & \multicolumn{3}{|c|}{ Measurements } \\
\hline Loading conditions & Light-ship & Ballast & Full load \\
\hline Free oscillation tests & Heave test & Pitch test & -- \\
\hline Regular wave tests (model scale) & $0.215 \mathrm{~m}$ & $0.518 \mathrm{~m}$ & $0.792 \mathrm{~m}$ \\
\hline Effect of wave height & Range from $0.038 \mathrm{~m}$ to $0.40 \mathrm{~m}$ (model scale) \\
\hline
\end{tabular}




\subsection{Swing tests}

Moments of inertia of the model were measured via inertia swing tests which were carried out at KHL. These tests were carried out to estimate heave and pitch moments of inertia. Based on the symmetrical shape of the cylindrical platform, pitch and roll radii of gyration are considered to be equal. In order to adjust the radii of gyration of the model in heave and pitch motions, swing test was used as shown in Figure 9. The pitch radius of gyration (kyy) was determined on the basis of 10 oscillations period. Both tests were repeated three times to obtain reasonable repeatability and obtained radii of the bare model are given in the Table 5 .

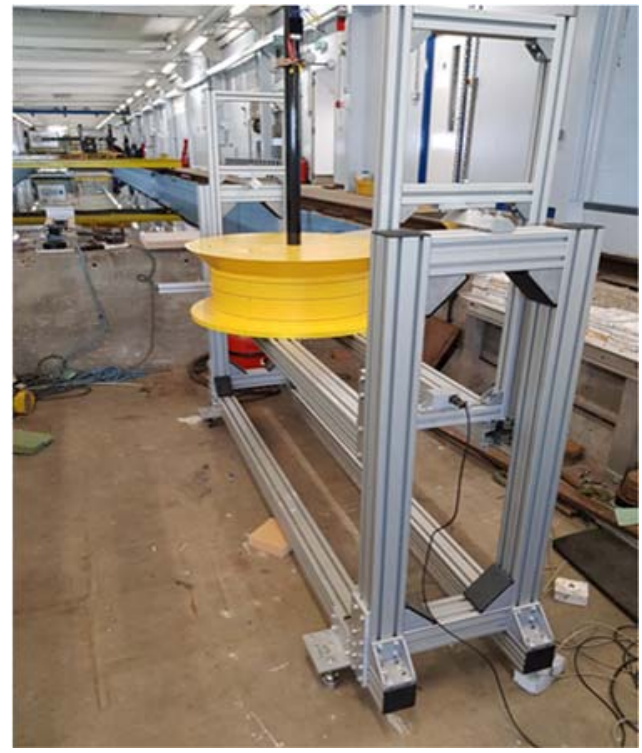

Figure 9: Swing table.

The longitudinal centre of gravity (LCG) of the model was set to be at the centre of the symmetrical cylindrical model. An inclining test was carried out using the swing table device to determine the Vertical Centre of Gravity (VCG) of the model.

Table 5: Model swing test results

\begin{tabular}{|c|c|c|c|}
\hline Loading condition & lightship & ballast & full load \\
\hline Mass (kg) & 25.0045 & 61.1597 & 86.0097 \\
\hline $\begin{array}{l}\text { Measured VCG }(\mathrm{m}) \text { from base of the } \\
\text { heave plate }\end{array}$ & 0.188 & 0.138 & 0.150 \\
\hline Measured Iyy $\left(\mathrm{kg} . \mathrm{m}^{2}\right)_{-}$ & 2.168 & 3.45 & 2.957 \\
\hline Target VCG (unit) & 0.1899 & 0.139 & 0.150 \\
\hline Target Iyy $\left(\mathrm{kg} . \mathrm{m}^{2}\right)_{-}$ & 1.60425 & 3.499788116 & 2.89166 \\
\hline ABS Difference in VCG $(\mathrm{mm})$ & -0.00187 & -0.000375 & $-2.08 \mathrm{E}-05$ \\
\hline ABS Difference in Iyy $\left(\mathrm{kg} . \mathrm{m}^{2}\right)$ & 0.564 & -0.0497 & 0.06526 \\
\hline Relative difference in VCG \% & $-0.986 \%$ & $-0.270 \%$ & $-0.014 \%$ \\
\hline Relative difference in Iyy \% & $35.15 \%$ & $-1.42 \%$ & $2.26 \%$ \\
\hline Radius of gyration (model scale) & 0.2533 & 0.2392 & 0.1833 \\
\hline
\end{tabular}

The radius of gyration obtained from the numerical model and the scaled results from the experiments are given in Table 5. The radius of gyration (Iyy) obtained from the numerical model shows reasonable correlation with experimental measurements in ballast and full load conditions. On the other hand, in 
light-ship case results obtained from experiments are slightly higher than those of the numerical simulation due to the difficulty to distribute the ballast weights in this case.

\subsection{Decay Tests in Still Water}

In order to identify the model natural frequency and damping ratio of floating platform models under finite translational and angular excitations in single degree-of-freedom mode, free decay tests were performed for all load conditions. For the heave motion decay, the model was submerged and carefully released vertically into water tank and the displacements in z-direction were recorded as shown in Figure 10 (a), (c) and (e). For the pitch motions, the model was released at a fixed tile angle along y direction and the angular displacements were recorded. Due to the symmetrical shape of the platform, roll and pitch are considered to be the same responses. The present experiment focuses on pitch and heave responses.

Data fitting has been applied and the fitted data were used to estimate the natural frequency and the damping ratio of the system based on a single DOF damped spring-mass model where free oscillation can be described with a second-order ordinary equation as [33]:

$\left(\frac{1}{\omega_{n}^{2}}\right) \ddot{x}+\left(\frac{2 \zeta}{\omega_{n}}\right) x+\dot{x}=0$

where $\omega_{n}$ is the natural frequency of the system and $\zeta$ is the damping ratio. The natural frequency and damping ratio of the system can be estimated as:

$\omega_{n}=\frac{\sqrt{4 \pi^{2}+\delta^{2}}}{T}$

$\zeta=\frac{\delta}{\sqrt{4 \pi^{2}+\delta^{2}}}$

where $T$ is the period of the oscillation signals and $\delta$ is the logarithmic decrements. The natural frequency, natural periods and damping ratio of the three load cases are listed in Table 6 .

Table 6: Free decay test results for different loading conditions.

\begin{tabular}{|l|l|c|c|c|}
\hline Loading condition & DoF & $\begin{array}{c}\text { Model damping } \\
\text { coefficient }(\zeta)\end{array}$ & $\begin{array}{c}\text { Full scale natural } \\
\text { frequency }\left(\omega_{n}\right) \mathrm{Hz}\end{array}$ & $\begin{array}{c}\text { Full scale natural } \\
\text { period [s] }\end{array}$ \\
\hline \multirow{2}{*}{ Light-ship } & Heave & 0.1980 & 0.0718 & 13.92 \\
\cline { 2 - 5 } & Pitch & 0.0670 & 0.0456 & 21.92 \\
\hline \multirow{2}{*}{ Ballast } & Heave & 0.0507 & 0.0698 & 14.32 \\
\cline { 2 - 5 } & Pitch & 0.0245 & 0.0461 & 21.69 \\
\hline \multirow{2}{*}{ Full load } & Heave & 0.0731 & 0.0644 & 15.52 \\
\cline { 2 - 5 } & Pitch & 0.0281 & 0.0492 & 20.32 \\
\hline
\end{tabular}

\section{Numerical modelling of FDP}

The primary numerical tool used in this study is the DNV-GL's Sesam, which is a well-recognized software by offshore, oil and gas industry and academia. The Sesam package contains several software modules which are used in design, simulation and evaluation of marine offshore structures. Sesam package is ideally suited for numerical simulation and calculation of motion responses of any fixed or floating structure. GeniE module is the primary software where the platform hull was modelled. The GeniE modeller allows for the creation of three-dimensional models, meshing and then transition of that model into other software solver. HydroD software is a numerical software solver in the frequency domain which allows for linear approximation to the equation of motion. In this study, the linear frequency domain package, HydroD, is used to calculate the platform's motion responses. Since The so 
called Response Amplitude Operator (RAO) was then calculated based on the motion responses and results are compared with experimental data.

The platform models were generated using GeniE modeller V7.4-18 software using 3D diffraction panels where panels represent the outer geometry of the platform structures. The wetted surface of the platform has been discretised into panel sizes of $0.1 \mathrm{~m}$. Material properties were assigned to the plate and the model was scaled up to the required mass density for each model. The frequency domain analysis was performed using HydroD V4.9-02. Frequency step setup was set at $0.01 \mathrm{rad} / \mathrm{sec}$.

\section{Results and discussion}

\subsection{Motion RAOs}

In this section the motion RAOs obtained from the experiments were compared to those from the numerical results for $0^{\circ}$ head seas. All of the motion responses show good agreement between numerical and experimental results for full scale wave periods between 7 to 33 seconds as shown in Figure 10. The heave and pitch motions in all loading conditions give the closest agreement between the measurements and numerical predictions over the whole range of wave periods except the peak spike. As expected, for the peak of heave and pitch responses, the numerical predictions substantially overestimate the experimental values particularly in the region of the natural period where damping dominates. As reported in Wayman et al. [34] the RAO shows a large spike due to damping effect on this spike at around its natural frequency similar to the results presented here. The results showed that as viscous damping increases, the peak responses decrease. This explains the overestimated RAO values around the heave and pitch natural periods. As mentioned previously, the HydroD software used for this study is a linear solver and did not allow additional viscous hydrodynamic damping to be deployed in the solution of the platform motions and it is presumed that this lack of viscous effects leads to the overestimation of the heave and pitch responses at the peak of the RAO. The y-axis was adjusted in Figure 10 in order to increase the comparison quality due to high numerical peak value. While the complete numerical curves were shown in Figure 11 for all cases. It is interesting to note that the agreement between experiments and numerical prediction for the remaining periods is much better than the peak giving more confidence in the numerical prediction. The largest heave motion response was observed for the full load case whereas largest pitch motion response was observed for the ballast case. The light-ship shows the smallest responses. It can be found that the heave motion has the peak response at a frequency of around $0.07 \mathrm{~Hz}$ and the pitch motion has a peak response at $0.045 \mathrm{~Hz}$ as shown in Figure 10 (a) and (b). 


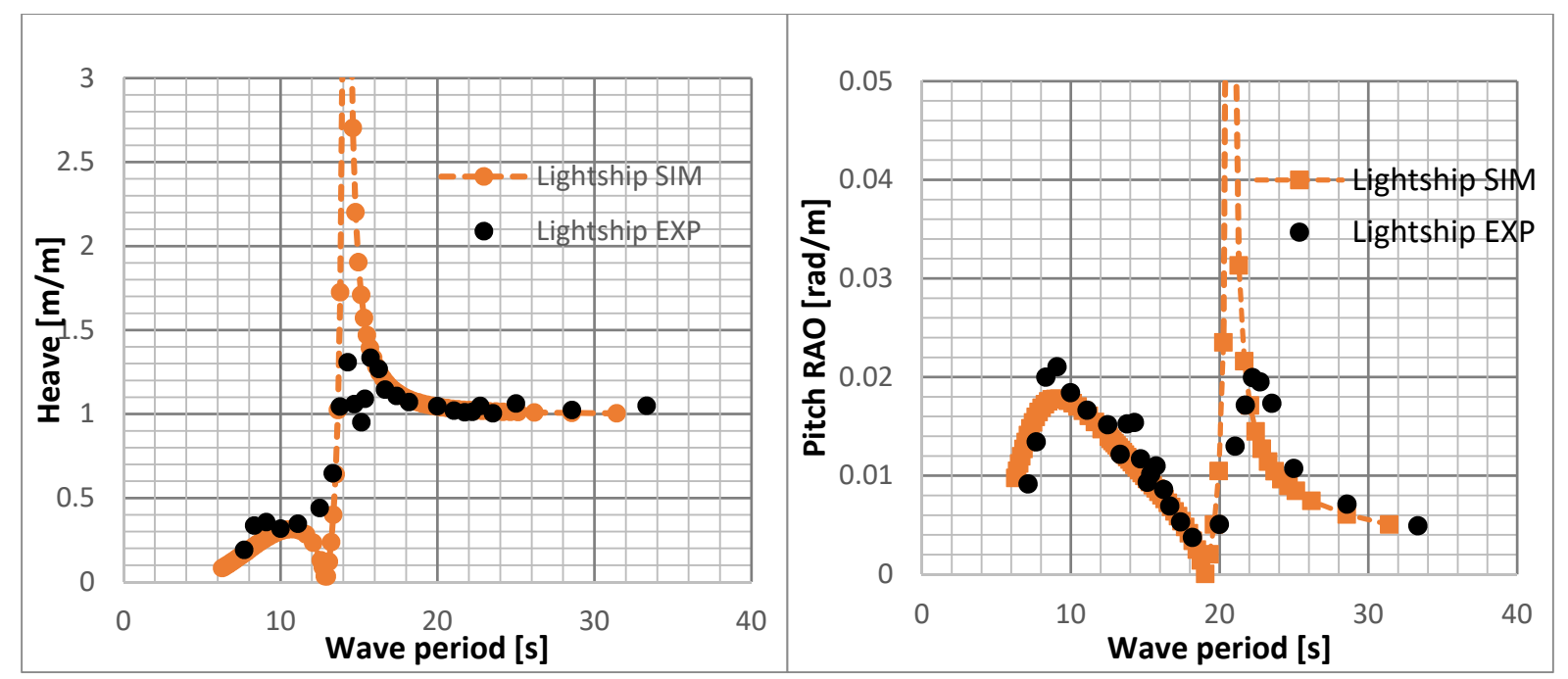

(a) heave RAO of light-ship condition

(b) Pitch RAO of Light-ship condition
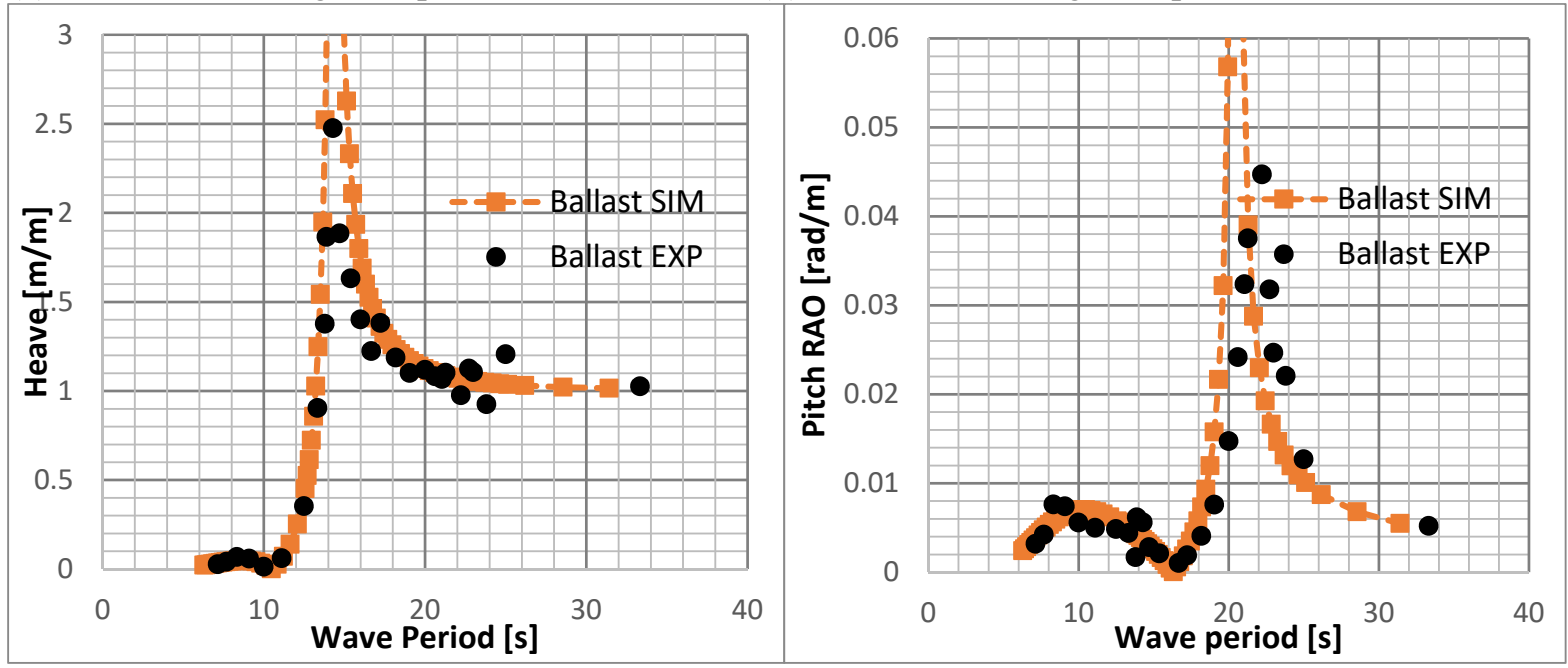

(c)heave RAO of ballast condition

(d) Pitch RAO of ballast condition
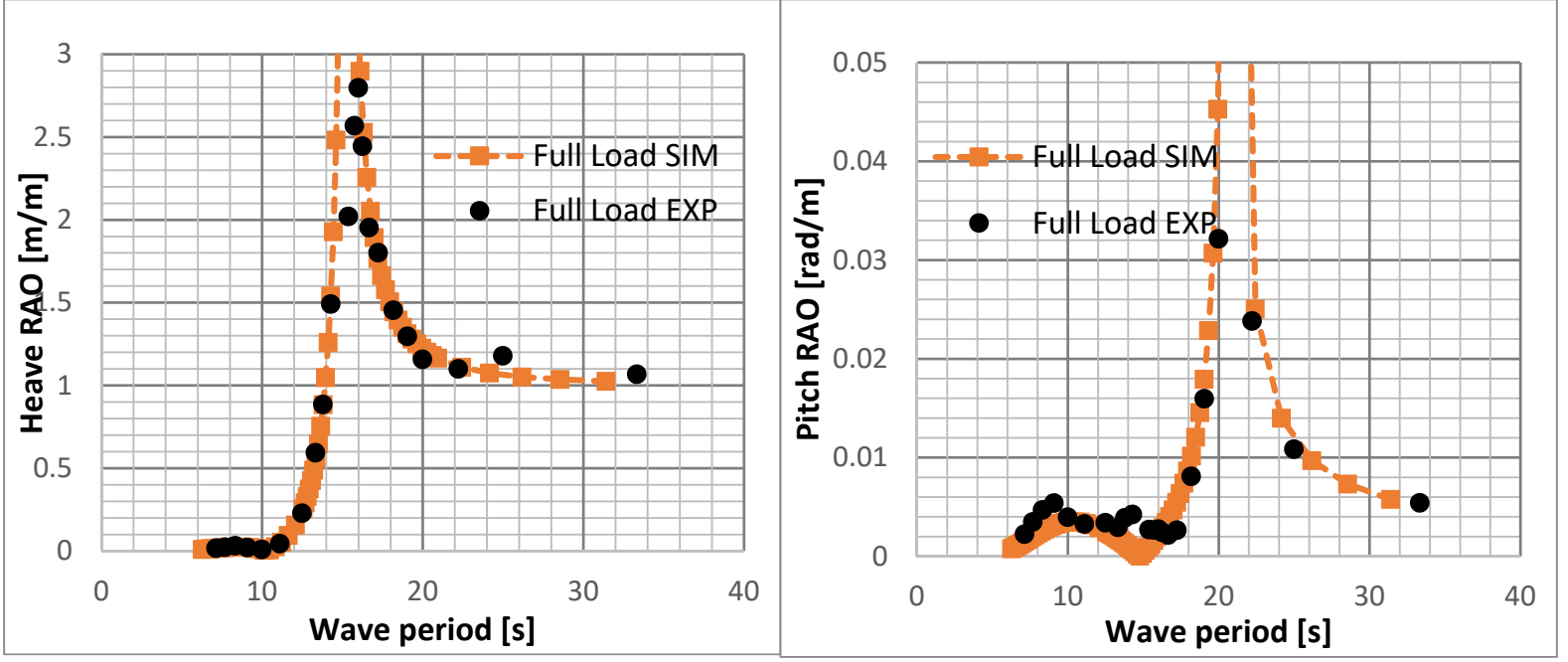

(e) heave RAO of full load condition

(f) Pitch RAO of full load condition

Figure 10: Motion responses of floating platform against wave period in different load conditions. (a) heave motion of light-ship case; (b) pitch motion of light-ship case; (c) heave motion of ballast case; (d) pitch motion of ballast case; (e) heave motion of full load case; (f) pitch motion of full load case. 


\subsection{Loading effect}

In order to present the effect of change in load conditions during the plant operation on the heave and pitch motions, comparison of all loading cases is shown in Figure 11 and Figure 12. Figure 11 presents the numerical comparisons of light-ship, ballast and full load conditions. It can be observed that the effect of change in load condition does not significantly affect the pitch peak response frequency as shown in Figure 11 (b) (stay around $0.045 \mathrm{~Hz}$ ). While, the damped natural frequencies are shifted in heave responses with about $9 \%$ for the full load case with respect to the light-ship case. The same observation occurs in the experimental results comparison where the pitch motion peak frequency is almost the same while heave motion is shifted with about $12 \%$ in the case of full load with respect to the light-ship case as shown in Figure 12 (a) and (b).

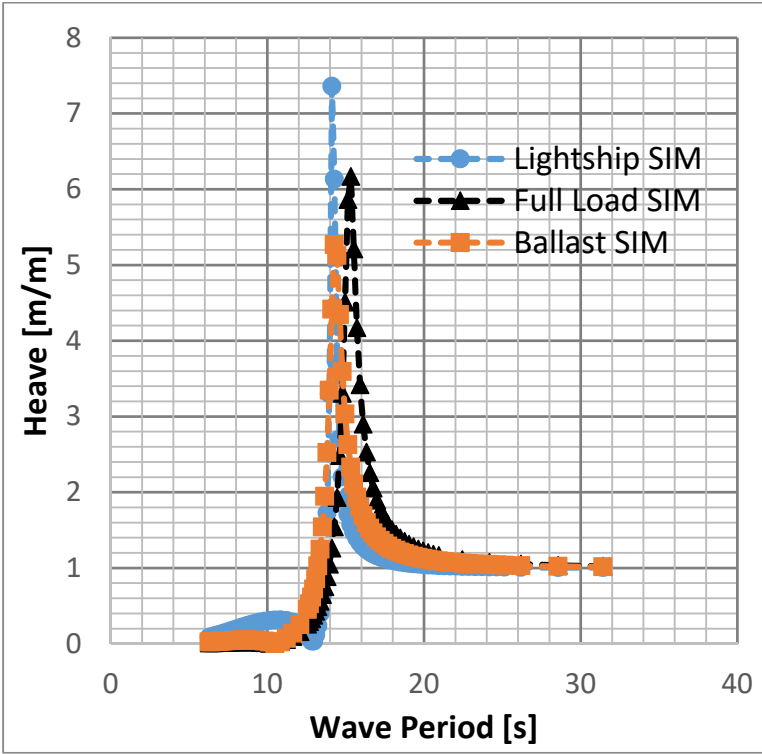

(a)

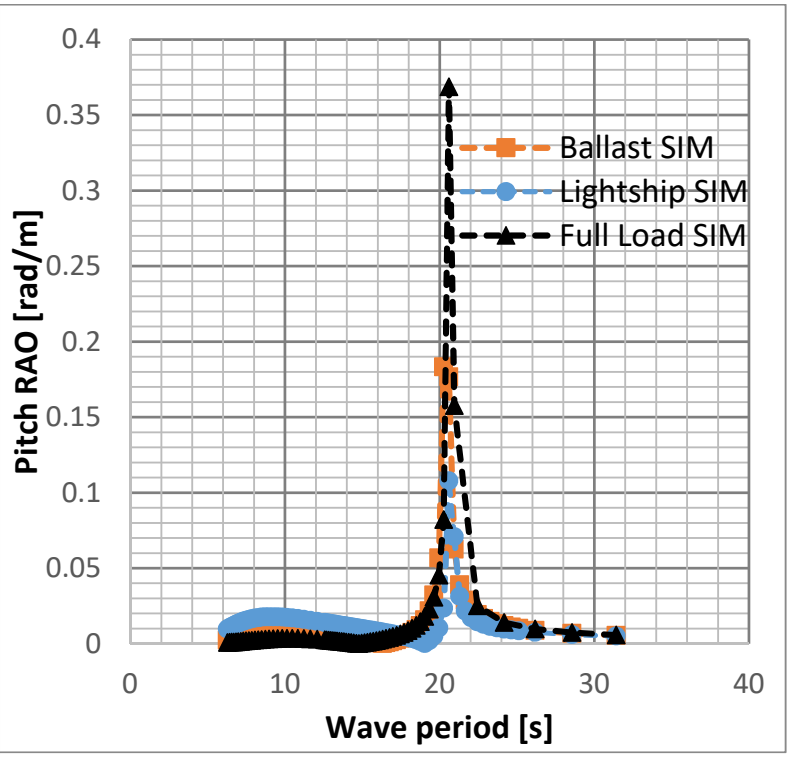

(b)

Figure 11: Comparison of numerical solution of motion responses for different load conditions; (a) heave RAO; (b) pitch RAO

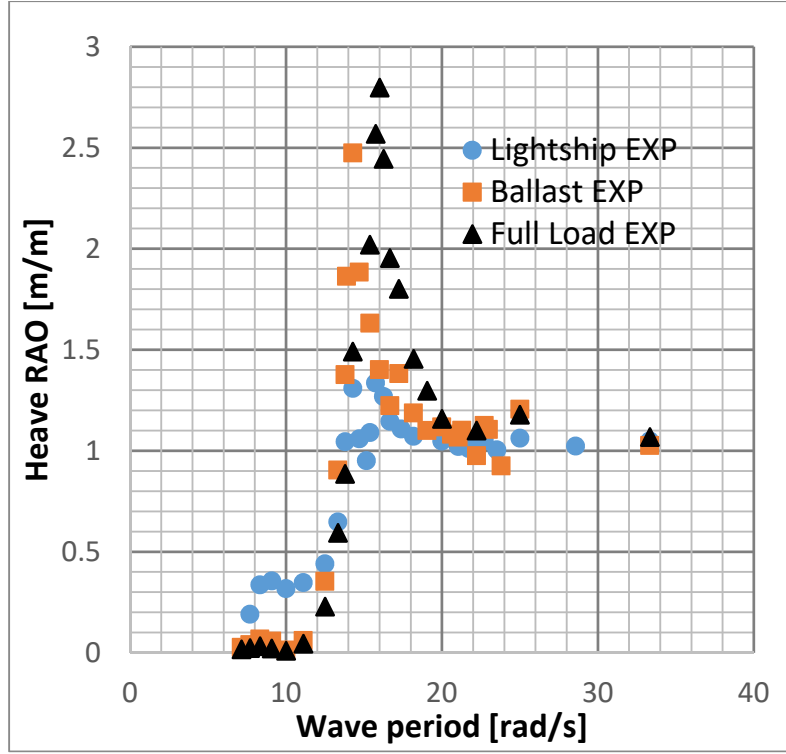

(a)

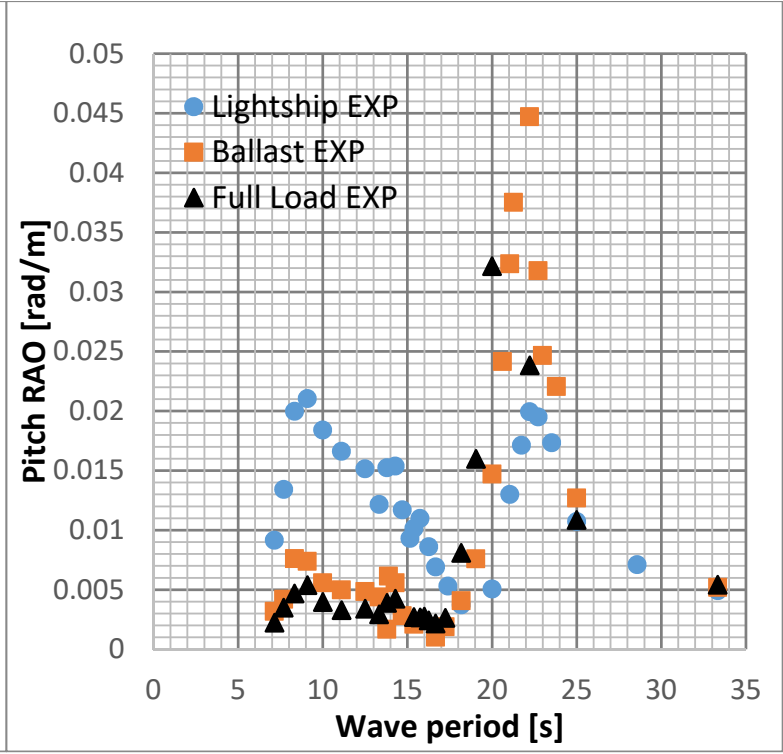

(b)

Figure 12: Comparison of experimental results of motion responses for different load conditions; (a) heave RAO; (b) pitch RAO 
Figure 12 (a) shows that pitch responses for light-ship condition are slightly larger than the ballast and full load conditions at most of tested frequency range. This observation could be useful for towing mode of the full scale platform.

\subsection{Effect of wave height}

Figure 13 shows the heave and pitch responses of the model with different wave heights. Three different wave heights in full scale design were tested as $2.15 \mathrm{~m}, 5.18 \mathrm{~m}$ and $7.92 \mathrm{~m}$ for the full load and the ballast conditions whereas wave heights of $1 \mathrm{~m}, 2.15 \mathrm{~m}$ and $3 \mathrm{~m}$ were tested for the light-ship condition due to the limited draft of water between heave plate and water surface. It can be observed that the effect of wave height on heave and pitch responses is very evident at natural frequency. However, for the remaining frequency ranges, the motion responses are not significantly different. In the full load case, the heave responses increase significantly with the increase of wave frequency before reaching its peak at $0.0625 \mathrm{~Hz}$. Afterwards, as frequency becomes larger than 0.0625 , the heave RAO decreases rapidly until it reaches near zero response. In the heave response of the full load case, as the wave height increases, the heave peaks keep a slow reduction.

In the pitch responses for all loading conditions, it can be observed that small secondary peak appears near $0.07 \mathrm{~Hz}$. The secondary peak height increases slightly with increase in the wave height as shown in Figures 13 (b), (d) and (e). In the light-ship condition as shown in Figure 13 (e), it is interesting to note that the single heave peak is converted into two peaks which looks like a $\mathrm{V}$ shape curve. The wave interactions between heave plate and water surface may possibly lead to this phenomenon. This will be further investigated in a future work.

In Figure 14, the relationship between the wave height and the heave responses at the model natural frequency is demonstrated. It can be observed that as the wave height amplitude increases, heave peaks decrease slightly for all load conditions. This is simply due to the fact that the viscous damping increases with the wave height. 

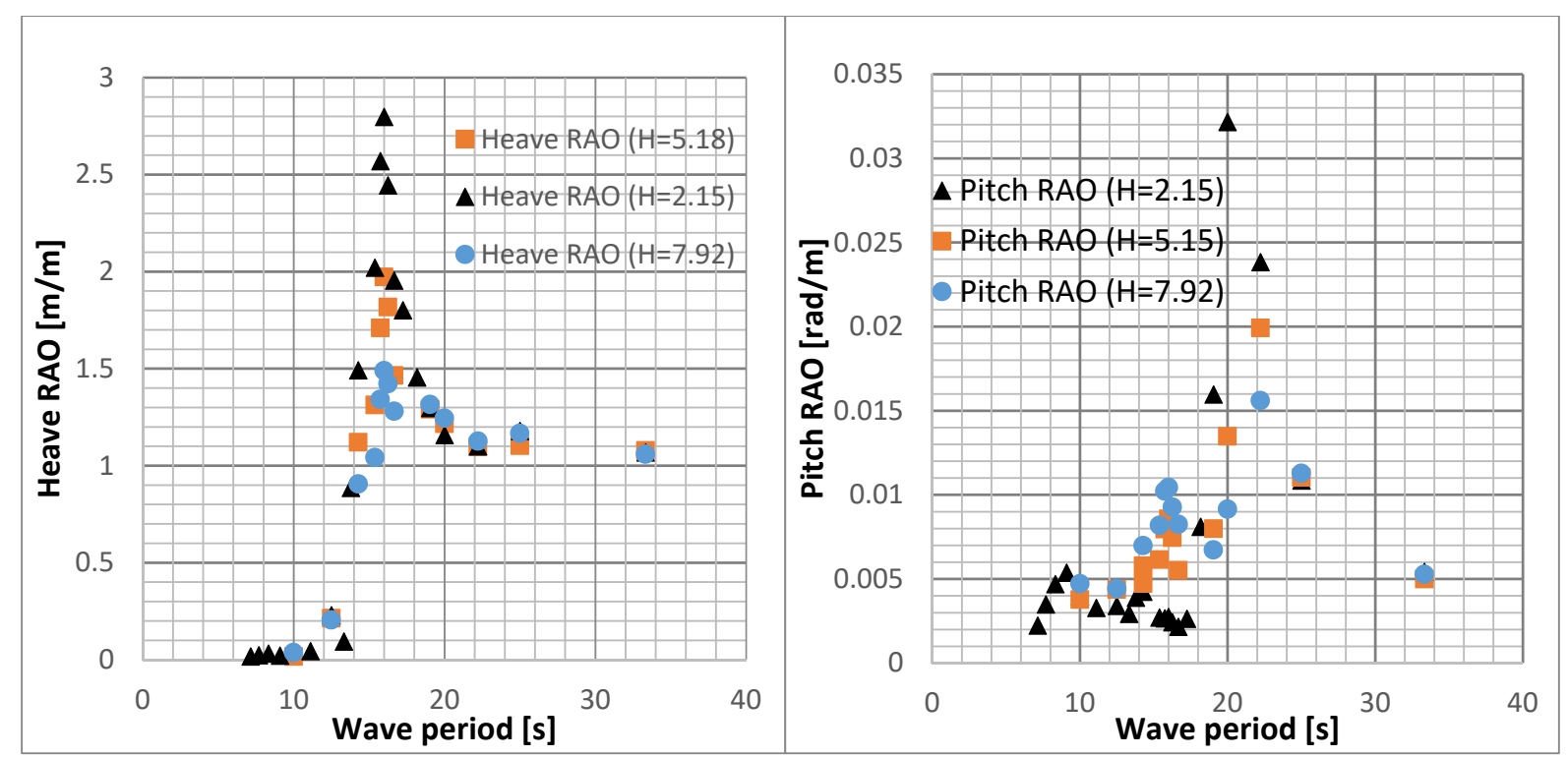

(a) Heave RAO for full load case

(b) Pitch RAO for full load case
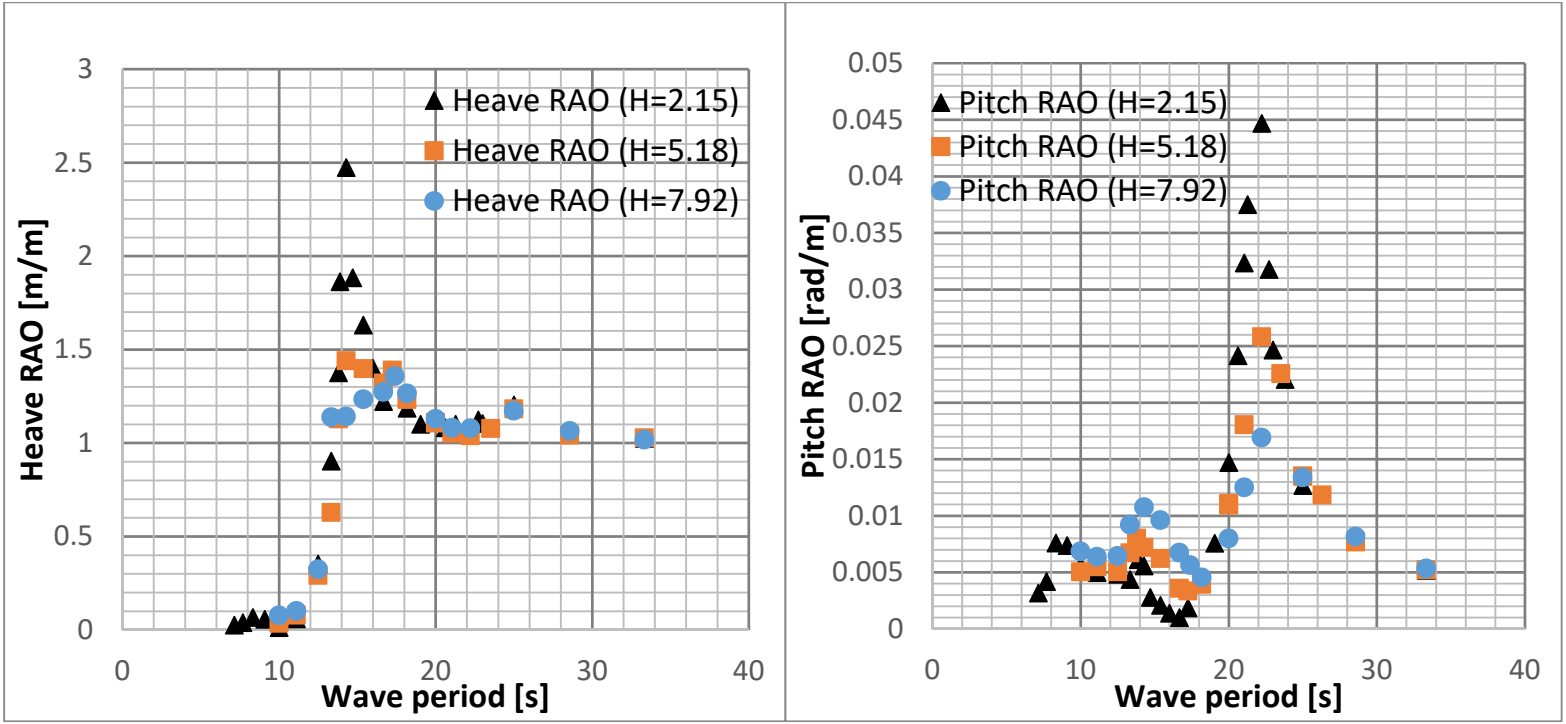

(c) Heave RAO for ballast case

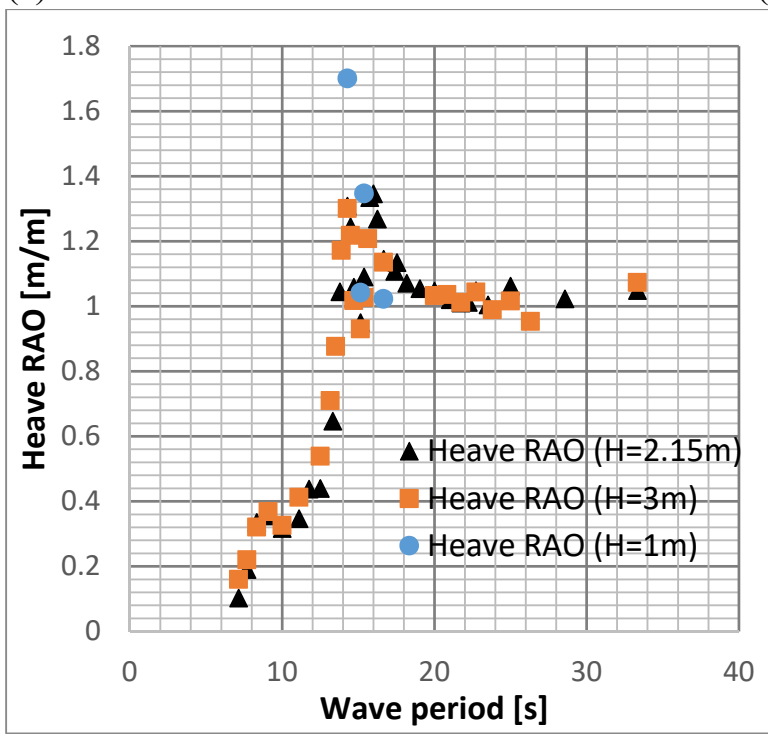

(d) Pitch RAO for ballast case

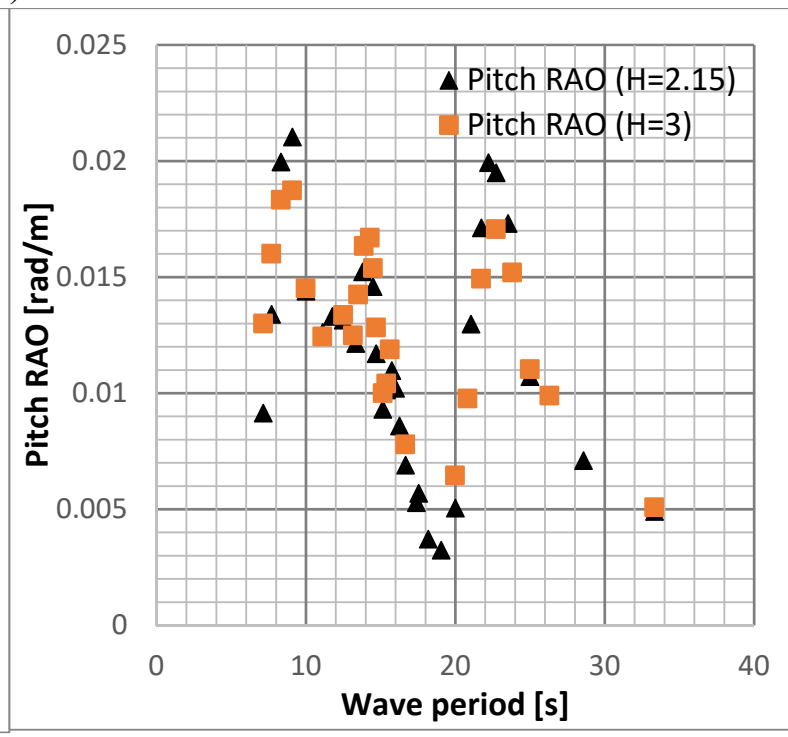

(e) Heave RAO for light-ship case

(f) Pitch RAO for light-ship case

Figure 13: The relationship between heave and pitch motion responses for different wave heights 


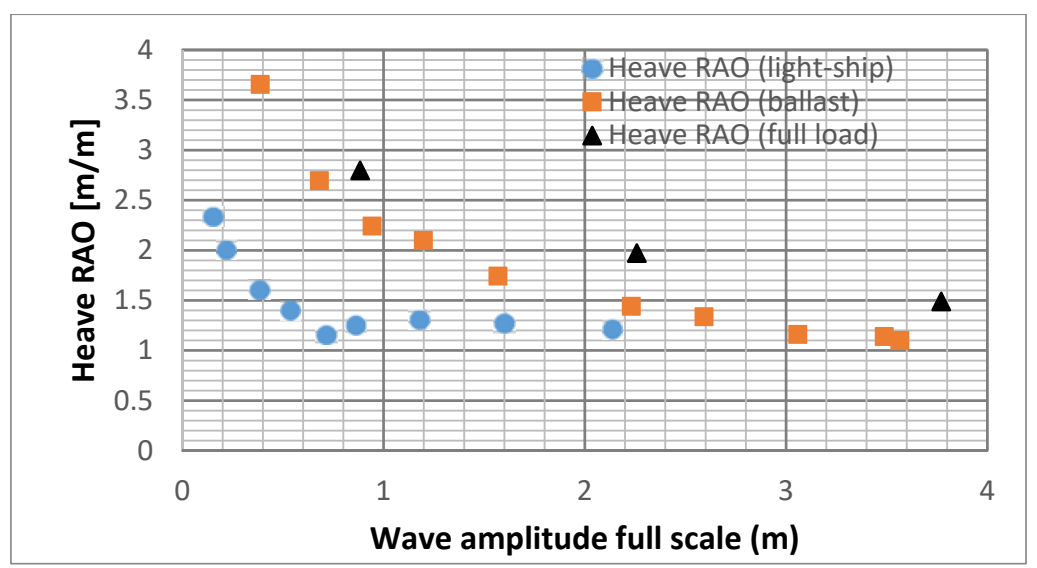

Figure 14: Effect of wave height on the heave RAO at peak frequency.

The free oscillation results show good correlation compared with the numerical and experiment approaches for all load conditions as shown in Table 7. The heave natural periods are in good agreement with $1.4 \%$ error for numerical results and $2.5 \%$ error for experimental approach for light-ship loading condition. For the pitch natural frequency, the error is $0.238 \%$ in experimental approach and $4.09 \%$ in numerical approach. Ballast and full load results are also shown in Table 7. Both natural periods (4.5 seconds for heave and 2.8 seconds for pitch) are outside of the regions where the influence of waves is significant (5.08 to 8 seconds).

Table 7: Comparison of natural frequencies of free decay obtained from numerical solution and experimental test results for different load conditions and its error percentages referred to decay test results

\begin{tabular}{|l|c|c|c|c|c|c|c|c|c|c|}
\hline \multirow{2}{*}{ load case } & \multicolumn{2}{|c|}{ decay tests } & \multicolumn{2}{c|}{$\begin{array}{c}\text { numerical } \\
\text { results }\end{array}$} & \multicolumn{2}{c|}{$\begin{array}{c}\text { experimental } \\
\text { test results }\end{array}$} & \multicolumn{2}{c|}{ numerical error \% } & \multicolumn{2}{c|}{ experimental error \% } \\
\cline { 2 - 12 } & heave & pitch & heave & pitch & heave & pitch & heave & pitch & heave & pitch \\
\hline light-ship & 0.072 & 0.046 & 0.071 & 0.049 & 0.070 & 0.045 & 1.392 & 2.506 & 2.506 & 1.445 \\
\hline ballast & 0.070 & 0.046 & 0.070 & 0.048 & 0.070 & 0.046 & 0.157 & 4.090 & 0.157 & 0.238 \\
\hline full load & 0.064 & 0.049 & 0.0652 & 0.049 & 0.064 & 0.050 & 1.148 & 1.480 & 1.489 & 1.564 \\
\hline
\end{tabular}

\subsection{Suitability of proposed FDP concept for Ras Ghareb area}

As mentioned before in introduction section, desalination ship is the most common concept presented for offshore freshwater production. According to the typical natural periods of deep water floaters presented by DNV GL [35], the FPSO ships have their periods of horizontal motions (surge, sway and yaw) greater than 100s; hence they are 'soft' motion in horizontal plane far from any wave excitation forces. While, FPSO ships have considerably varying periods of motions in vertical plane (roll, pitch \& heave) which could be near to wave excitation forces as shown in Table 8 . If the wave period matches with the natural period of the FPSO then resonance would occur.

In order to evaluate the suitability of the proposed FDP concept for Ras Ghareb deployment area, heave and pitch motion responses were compared with wave excitation bands in Ras Ghareb area as shown in Figure 15. Moreover, the proposed concept was compared with ship FPSO called West Navigator in beam direction. The West Navigator displacement has same displacement of proposed cylindrical plant in full load condition, while has $253 \mathrm{~m}$ length and $42 \mathrm{~m}$ breadth. Based in wave spectrum analysis in Figure 4 and the wave period information in Red Sea zone, Ras Ghareb wave bands range were plotted as a blue box in the figure (from $3 \mathrm{~s}$ to $12.5 \mathrm{~s}$ ). The comparison shows that the heave period (about $10 \mathrm{~s}$ ) of ship FPSO was lied in the same spectrum of the Ras Ghareb sea energy, while the proposed cylindrical plant motion has been out of wave excitation forces in this area. 
Table 8 - Typical floaters natural periods [35]

\begin{tabular}{|l|l|l|l|l|}
\hline Mode & Semi-Sub & FPSO & TLP & Spar \\
\hline Surge & $>100$ & $>100$ & $>100$ & $>100$ \\
\hline Sway & $>100$ & $>100$ & $>100$ & $>100$ \\
\hline Yaw & $>100$ & $>100$ & $>100$ & $>100$ \\
\hline Roll & $30-60$ & $5-30$ & $<5$ & $50-90$ \\
\hline Pitch & $30-60$ & $5-12$ & $<5$ & $50-90$ \\
\hline Heave & $20-50$ & $5-12$ & $<5$ & $20-35$ \\
\hline
\end{tabular}
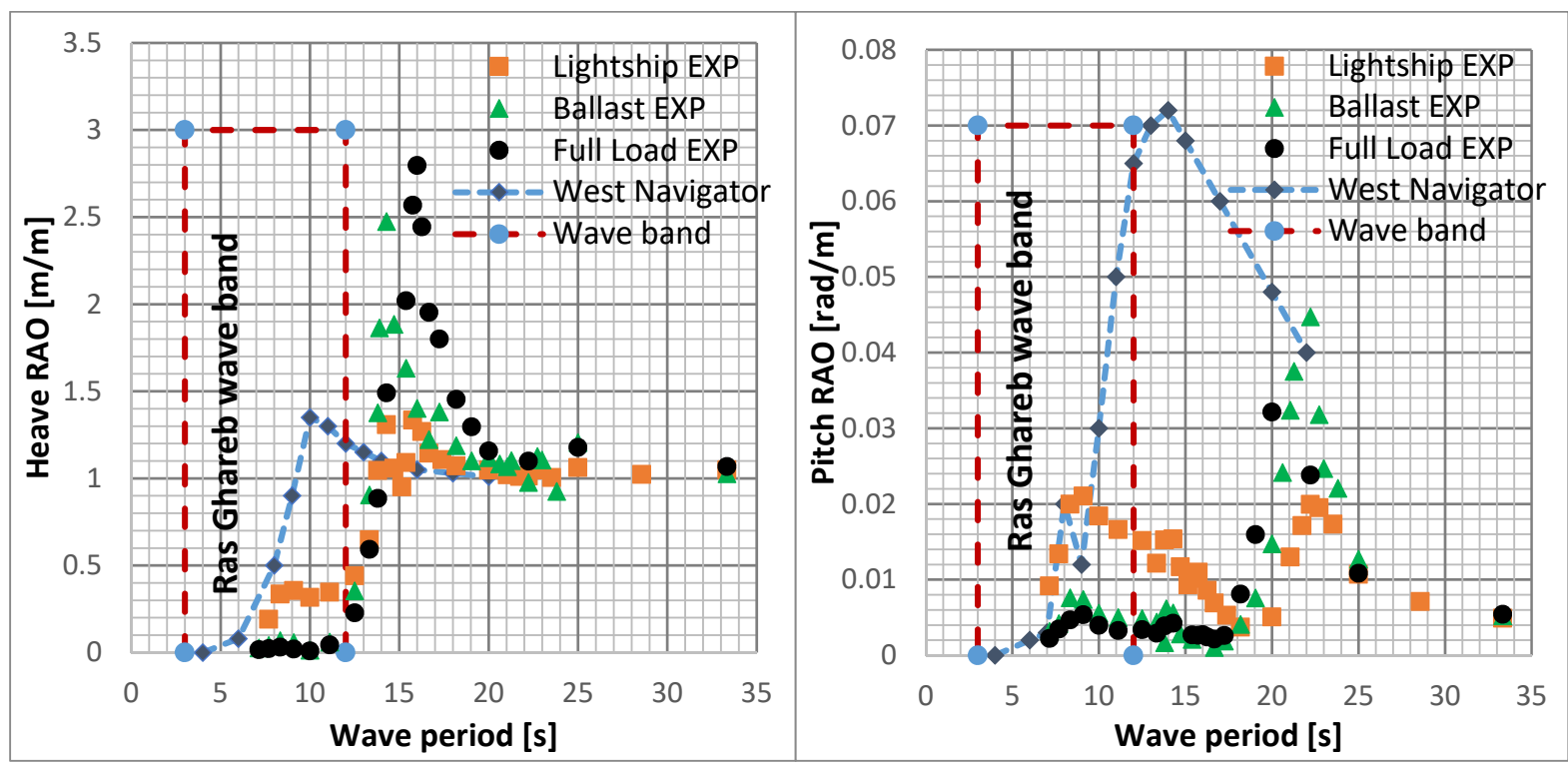

(a) Heave RAO

(b) Pitch RAO

Figure 15: suitability of proposed FDP concept for Ras Ghareb area.

\section{Conclusion}

A novel cylindrical FDP concept was proposed to overcome the freshwater storage of remote coastal area in Egypt. Each deployment area has its excitation wave bands, which should not be compatible with the floater natural periods to avoid resonance responses. Therefore, the present study describes the motion behaviour of the proposed concept in simulated working conditions using both experimental and numerical approaches. The results from both approaches were presented and compared for a range of wave heights and periods considering Egyptian environmental conditions. The tests consisted of swing tests, free decay test in heave and pitch and regular wave tests. All of the motion responses showed good agreement between experimental and numerical results for wave periods between 7 to 33 seconds and different wave heights but the numerical results significantly overestimate the motion responses near heave and pitch natural period. Moreover, the results from extreme case (wave height $7.92 \mathrm{~m}$ ) showed that secondary peak occurred in experiments results and was not captured by the numerical predictions.

The wave height effects the RAO results at the heave and pitch natural frequencies. Increase in the wave heights leads to slight decrease in heave peaks for all load conditions. Changing the load condition does not significantly affect the pitch peak response frequency. While, in heave motion, it has shifted about $12 \%$ for the full load case with respect to the light-ship case. 
For all load conditions and wave heights, the natural periods of proposed plant were outside of the high energy excitation range of the wave in the deployment area, while the heave motion of the conventional ship FPSO concept was lied in the same wave bands. Therefore, the proposed cylindrical FDP concept is more suitable for Egyptian environmental conditions compared with conventional FPSO ship concept.

Further investigation is required to explain why the numerical predictions failed to accurately predict the platform response especially near the natural frequency of heave and pitch motions when the heave plate is near to water surface (light-ship case). Further experiments for irregular wave tests need to be considered in a future work to study the non-linearities of the proposed concept. Shallow water effects could be carried out in a future study to cover water depths of all potential sites. Although experimental study is a very costly and time consuming process compared to the relative ease of obtaining the numerical predictions, the results in the present study suggests that, until the numerical discrepancies are resolved, carefully conducted experiments which properly takes into account nonlinear effects are essential in order to characterise the performance of floating platforms. And further study is required to investigate the reason behind the difference between the numerical and experimental results.

\section{Acknowledgements}

The authors acknowledge the British Council and Science and Technological Development Fund (STDF) for supporting the project NO. 30707 (Mobile Reverse Osmosis Floating Desalination Platform Powered by Hybrid Renewable Energy). The authors acknowledge the University of Strathclyde's Department of Naval Architecture, Ocean and Marine Engineering and Desert Research Centre for the technical expertise and support provided during the period of research. The authors would also like to acknowledge the Kelvin Hydrodynamic Laboratory technician team including Steven Black, Grant Dunning, Bill Wright, Rebecca McEwan for their technical support through the model construction and experiment setup.

\section{References}

1- Fadel, M., Wangnick, K., and Wada, N., Floating desalination plants an engineering, operating and economic appraisal. Desalination Journal Vol 45, 1983, pp 49-63.

2- Chouski, B. AquaTDPB3DP plants and systems: floating modular dismountable desalination equipment. Desalination Journal, Vol 153, 2002, pp 349-354.

3- Chouski, B. AquaTDP/S3DP plants and systems. Floating ship-borne modular dismountable seawater desalination plant. Desalination, Vol. 165, 2004, pp 369-375.

4- Vasjukov, V., Klyikov, D., Podbereznyi, V. and Shipilov, V. Floating nuclear desalination plant AFWS-40. Desalination, Vol. 89, 1992, pp 21-32.

5- Babu, P.T.; Reddy, D.V. Existing Methodologies in the Design and Analysis of Offshore Floating Nuclear Power Plant. Nucl. Eng. Des. 1978, 48, 167-205.

6- Daltona, G.; Bardóczb, T.; Blanchc, M.; Campbelld, D.; Johnsone, K.; Lawrenceb, G.; Lilasf, T.; Friis- Madseng, K.; Neumannh, F.; Nikitasf, N.; et al. Feasibility of investment in Blue Growth multiple-use of space and multi-use platform projects; results of a novel assessment approach and case studies. Renew. Sustain. Energy Rev. 2019, 107, 338-359.

7- Chun-Yan Ji, Yu-Chan GUO, Jie Cui, Zhi-Ming Yuan, Xiao-Jian Ma. 3D experimental study on a cylindrical floating breakwater system. Ocean Engineering Journal, Vol. 125, 2016, pp 38-50.

8- Sining Zheng, Yongliang Zhang. Analysis for wave power capture capacity of two interconnected floats in regular waves. Journal of Fluids and Structures, Vol. 75, 2017, pp 158-173. 
9- Xinjie Ji, Yan Li, Yougang Tang, Qiang Zhu, Zhiqiang Hu. Damping performance of annular antimotion structures on a cylindrical floating drilling production storage and offloading system. Ocean Engineering, Vol. 192, 2019, 106590.

10- Rodolfo T. Gonçalves, Fabio T. Matsumoto, Edgard B. Malta, Guilherme F. Rosetti, André L. C. Fujarra \& Kazuo Nishimoto. Evolution of the MPSO (monocolumn production, storage and offloading system). Marine Systems \& Ocean Technology, volume 5, pp 45-53, 2009.

11- A. C. Saad, L. Vilain, R. R. Loureiro, R. M.Brandão, R. Z. Machado Filho, C. Lopes, H. Gioppo. Marine Motion Behaviour of the Mono-Column FPSO Sevan Piranema in Brazilian Waters. Offshore Technology Conference held in Houston, Texas, USA, 4-7 May 2009.

12- Rodolfo T. Gonçalves, André L. C. Fujarra, Guilherme F. Rosetti1, Kazuo Nishimoto, Marcos Cueva and Elizabeth F. N. Siqueira. Vortex-Induced Motion of a Monocolumn Platform: New Analysis and Comparative Study. Proceedings of OMAE2009, 28th International Conference on Ocean, Offshore and Arctic Engineering, 31 May - 5 June 2009, Honolulu, Hawaii.

13- Wenbo Pan, Ningchuan Zhang, Guoxing Huang, Xiangyu Ma. Experimental study on motion responses of a moored rectangular cylinder under freak waves (I: Time-domain study). Ocean Engineering, Vol. 153, 2018, pp 268-281.

14- Wenyue Lu, Xin Li, Xiantao Zhang, Xinliang Tian, Xiaoxian Guo. Experimental study on the wave run-up and air-gap response of a three-column semi-submersible platform. Ocean Engineering, Vol. 203, 2020, pp 107-253.

15- Hanbin Gu, Peter Stansby, Tim Stallard, Efrain Carpintero Moreno. Drag, added mass and radiation damping of oscillating vertical cylindrical bodies in heave and surge in still water. Journal of Fluids and Structures, Vol. 82, 2018, pp 343-356.

16- K.F. Cheung, A.C. Phadke, D.A. Smith, S.K. Lee, L.H. Seid. Hydrodynamic response of a pneumatic floating platform. Ocean Engineering, Vol. 27, 2000, pp 1407-1440.

17- Zhang Chi, Allan R Magee, Wan Ling, Chien Ming Wang, Øyvind Hellan. EXPERIMENTAL STUDY OF HYDRODYNAMIC RESPONSES OF A SINGLE FLOATING STORAGE TANK WITH INTERNAL FLUID. Proceedings of the ASME 2017 36th International Conference on Ocean, Offshore and Arctic Engineering, OMAE2017, June 25-30, 2017, Trondheim, Norway.

18- Experimental study on hydrodynamic performance of a new type of deep draft multi-column FDPSO. Journal of Marine Science and Technology, Vol. 25, No. 3, pp. 329-342 (2017)

19- Wen-hua Wang, Lin-lin Wang, Ya-zhen Du, Yu-xin Yao, Yi Huang. Numerical and experimental analysis on motion performance of new sandglass-type floating body in waves. Marine Structures, Vol 46, 2016, pp 56-77.

20- Adeleh Graylee and Mahdi Yousefifard. Numerical Analysis of the Effects of Sandglass-Type FPSO Hull Form on Hydrodynamic Performance in Regular Waves. Journal of Coastal and Marine Engineering, Volume 1, Number 1, June 2018.

21- Lin-lin Wang, Wen-hua Wang, Ya-zhen Du, Hao Gao and Yi HuangPitch. motion problem induced by dynamic positioning system for new sandglass-type floating body. J Mar Sci Technol (2017) 22:162175.

22- Wen-Hua Wang, Ya-Zhen Du, Lin-Lin Wang and Yi Huang. Wave-free characteristic of heave motion response for new sandglass-type model. Ships and Offshore Structures, 13:2, pp 181-193, 2017. 
23- Zhen Gaoa, Torgeir Moan, Ling Wan, Constantine Michailides. Comparative numerical and experimental study of two combined wind and wave energy concepts. Journal of Ocean Engineering and Science, Vol.1, 2016, pp 36-51.

24- M. Kamarlouei, J.F. Gaspar, M. Calvario, T.S. Hallak, M.J.G.C. Mendes, F. Thiebaut, C. Guedes Soares. Experimental analysis of wave energy converters concentrically attached on a floating offshore platform. Renewable Energy, Vol. 152, 2020, pp 1171-1185.

25- Nianxin Ren, Zhe Ma, Baohua Shan, Dezhi Ning, Jinping Ou. Experimental and numerical study of dynamic responses of a new combined TLP type floating wind turbine and a wave energy converter under operational conditions. Renewable Energy, Vol. 151, 2020, pp 966-974.

26- Jens Hetland, Hanne Marie Kvamsdal, Geir Haugen, Fredrik Major. Integrating a full carbon capture scheme onto a 450 MWe NGCC electric power generation hub for offshore operations: Presenting the Sevan GTW concept. Applied Energy, Vol. 86, 2009, pp 2298-2307.

27- Islam Amin, Mohamed E.A. Ali, Seif Bayoumi, Selda Oterkus, Hosam Shawky and Erkan Oterkus. Conceptual Design and Numerical Analysis of a Novel Floating Desalination Plant Powered by Marine Renewable Energy for Egypt. Journal of marine science and engineering, Vol. 8, 2020, pp 95. (doi:10.3390/jmse8020095)

28- Ahmed, A. Electricity generation from the first wind farm situated at RasGhareb, Egypt. Renewable and Sustainable Energy Reviews, Vol. 16, 2012, pp 1630- 1635.

29- Ahmed, A. Investigation of wind characteristics and wind energy potential at RasGhareb, Egypt. Renewable and Sustainable Energy Reviews, Vol. 15, 2011, pp. 2750-2755.

30- Mahdy, M. and Bahaj, A. Multi criteria decision analysis for offshore wind energy potential in Egypt. Renewable Energy, Vol. 118, 2018, pp 278-289.

31- Xinjie Ji, Yan Li, Yougang Tang, Bo Tong. Viscous damping effect and vortex shedding performance of the novel anti-motion structures on a cylindrical FPSO. Ocean Engineering, Vol. 190, $2019,106430$.

32- Begovic, E. and Incecik, A. Experimental ship motion and load measurements in head and beam seas. IX HSMV conference, Naples, 25-27 May 2011.

33- Yan Zhang, Jiaming Zhao, Brandon Grabrick, Brandon Jacobson, Austin Nelson, John Otte. Dynamic response of three floaters supporting vertical axis wind turbines due to wind excitation. Journal of Fluids and Structures, Vol. 80, 2018, pp 316-331.

34- Wayman, E., Sclavounos, P., Butterfield, S., Jonkman, J., Musial, W., 2006. Coupled dynamic modeling of floating wind turbine systems. Offshore Technology Conference Houston, Texas.

35- DNV RP-F 205 “Global performance analysis of deep water floating structures”, October 2004. 